Maurer School of Law: Indiana University

Digital Repository @ Maurer Law

2019

Court Personnel Attitudes Towards Medication-assisted

Treatment: A Statewide Survey

Barbara Andraka-Christou

Meghan Gabriel

Jody L. Madeira

Rod D. Silverman

Follow this and additional works at: https://www.repository.law.indiana.edu/facpub

Part of the Courts Commons, Medical Jurisprudence Commons, Public Health Commons, and the Substance Abuse and Addiction Commons 


\title{
Court personnel attitudes towards medication-assisted treatment: A state- wide survey
}

\author{
Barbara Andraka-Christou $^{\mathrm{a}, *}$, Meghan Gabriel ${ }^{\mathrm{a}}$, Jody Madeira $^{\mathrm{b}}$, Ross D. Silverman ${ }^{\mathrm{c}}$ \\ ${ }^{a}$ Department of Health Management \& Informatics, University of Central Florida, United States of America \\ ${ }^{\mathrm{b}}$ Maurer School of Law, Indiana University-Bloomington, United States of America \\ ${ }^{c}$ Department of Health Policy \& Management, Indiana University Richard M. Fairbanks School of Public Health, United States of America
}

\section{A R T I C L E I N F O}

\section{Keywords:}

Courts

Medication-assisted treatment

Opioid use disorder

Medications for opioid use disorder

Survey

Beliefs

Attitudes

Buprenorphine

Methadone

Naltrexone

Education

Training

Criminal justice

\begin{abstract}
A B S T R A C T
Background: Despite its efficacy, medication-assisted treatment (MAT) is rarely available in the criminal justice system in the United States, including in problem-solving courts or diversionary settings. Previous studies have demonstrated criminal justice administrators' hostility towards MAT, especially in prisons and jails. Yet, few studies have examined attitudes among court personnel or compared beliefs among different types of personnel. Also, few studies have explored the relationship between MAT education/training and attitudes. Finally, few studies have directly compared attitudes towards methadone, oral buprenorphine, and extended-release naltrexone in the criminal justice system.

Methods: We modified a survey by Matusow et al. (2013) to explore justice professionals' MAT attitudes, including associations with demographic variables, court role, and previous MAT education/training. After piloting the survey, we distributed it to a convenience sample of justice professionals registered for an educational summit held in Indiana in 2018. Data was analyzed using descriptive and inferential statistical methods.

Results: 231 Indiana court employees who had registered for a state MAT educational summit completed the survey prior to the summit, including judges, probation officers, law enforcement personnel, attorneys, probation officers, program directors, counselors, and case managers. Overall, participants had significantly more positive attitudes towards extended-release naltrexone than towards other medications ( $p$ value $<0.01$ ). Court employee average attitudes towards methadone were significantly more negative than average attitudes towards oral buprenorphine; and average attitudes towards oral buprenorphine were significantly more negative than average attitudes towards extended-release naltrexone ( $p$ value $<0.01$ ). Employment as a prosecutor or law enforcement officer was associated with more negative attitudes towards oral buprenorphine and methadone $(p$ value $<0.05$ ). Exposure to previous MAT training was associated with more positive attitudes for all medications $(p$ value $<0.05$ ). Compared to participants with graduate degrees, participants with less education had significantly more negative attitudes towards extended-release naltrexone $(p<0.05)$. Gender, age, rurality, and personal/family recovery history were not associated with differences in attitudes.

Conclusion: As expected, court employees' attitudes significantly differ by medication, with average attitudes towards agonist medications being more negative than attitudes towards extended-release naltrexone. Despite a larger evidence base for the efficacy of methadone and oral buprenorphine, justice personnel may have more positive attitudes towards extended-release naltrexone due to targeted marketing by the pharmaceutical manufacturer, fears about diversion or misuse of agonist medications, and historic criminal justice hostility towards agonist medications. Importantly, previous education/training regarding MAT is associated with more positive attitudes, suggesting that more awareness-raising or capacity building educational interventions are needed, especially for prosecutors and law enforcement personnel.
\end{abstract}

\section{Introduction}

Approximately two million Americans have an opioid use disorder
(OUD) (National Institutes of Health, 2016). Individuals with OUD are at significant risk of opioid overdose, a particularly pressing problem in the U.S. where opioid-related death rates have quadrupled nationally

\footnotetext{
* Corresponding author at: Department of Health Management \& Informatics, University of Central Florida, 4364 Scorpius Street, HPA II Room 217, Orlando, FL 32816, United States of America.

E-mail address: Barbara.andraka@ucf.edu (B. Andraka-Christou).
} 
since 2000 (Dowell et al., 2017) and contributed to decreased average life expectancy (Dowell et al., 2017). Individuals with OUD are also overrepresented in the U.S. criminal justice system, with an estimated $24 \%$ to $36 \%$ of Americans with OUD cycling in or out of jail annually (Results from the 2012 National Survey on drug use and health: Summary of National Findings, 2013; Rich et al., 2005).

Evidence-based treatment for OUD includes three medications approved by the Food and Drug Administration: methadone, buprenorphine, and naltrexone (collectively referred to as medication-assisted treatment, or "MAT"). ${ }^{1}$ Although treatment should be individualized and include behavioral treatment (e.g. mental health therapy), MAT is more effective than behavioral treatment alone (Potter et al., 2013), and MAT is associated with significant decreases in opioid overdose rates, opioid misuse rates, criminal activity, and HIV/AIDS incidence (Jarvis et al., 2018; Kelty \& Hulse, 2017; Larochelle et al., 2018; Mattick, Breen, Kimber, \& Davoli, 2014; Sharma et al., 2016; Sordo et al., 2017). At moderate doses, methadone, a full opioid agonist, and buprenorphine, a partial opioid agonist, are considered equivalently effective at preventing opioid misuse and overdose, although some studies have found longer treatment retention rates with methadone (Mattick et al., 2014; Nielsen, Larance, \& Lintzeris, 2017). Methadone and buprenorphine have a stronger evidence base than does naltrexone, but extended-release naltrexone may be as effective as oral buprenorphine in preventing opioid misuse and overdose for some populations (Lee et al., 2018; Morgan, Schackman, Leff, Linas, \& Walley, 2018; Tanum et al., 2017). Unlike methadone, which may only be accessed via highly-regulated, stand-alone opioid treatment programs ("methadone clinics"), buprenorphine and naltrexone formulations may be accessed in office-based settings. However, to prescribe buprenorphine healthcare practitioners must obtain a waiver from the Substance Abuse and Mental Health Services Administration (SAMHSA) (Medications for Opioid Use Disorder TIP 63 Treatment Improvement Protocol For Healthcare and Addiction Professionals, Policymakers, Patients, and Families, 2018). Unlike buprenorphine or methadone treatment, naltrexone treatment requires complete detoxification prior to induction, which can be a significant hurdle for many people with OUD (Lee et al., 2017), especially given the undersupply and cost of inpatient detoxification services in many areas (Andraka-Christou \& Capone, 2018). Additionally, the injectable form of naltrexone is significantly more expensive than methadone and oral buprenorphine, both of which are available in generic formulations (Jackson, Mandell, Johnson, Chatterjee, \& Vanness, 2015).

Despite MAT's efficacy, it is significantly underused in U.S. drug courts, jails, and prisons (Hedrich et al., 2012; Ludwig \& Peters, 2014; Matusow et al., 2013; Nordstrom \& Marlowe, 2016; Nunn et al., 2009). According to one study, among criminal justice system participants referred to OUD treatment, only $5 \%$ received a referral for either buprenorphine or methadone treatment (Krawczyk, Picher, Feder, Student, \& Saloner, 2017). Furthermore, in that study participants who were referred to OUD treatment by problem-solving courts or other diversionary programs (e.g. programs where charges are dropped following successful treatment) were less likely to receive a referral for buprenorphine or methadone than were those who received a referral for OUD treatment from probation, parole, or prison (Krawczyk et al., 2017). Reasons for lack of MAT referral in the criminal justice system include negative attitudes towards MAT, such as beliefs that it is ineffective for OUD, has a high potential for misuse or diversion, is difficult to administer, and is costly (Bruce \& Schleifer, 2008; Friedmann et al., 2012; Gordon, Vocci, Fitzgerald, O'Grady, \& O'Brien, 2017;

\footnotetext{
${ }^{1}$ We use the term "medication-assisted treatment" throughout the manuscript to refer to methadone, buprenorphine, and naltrexone treatment, both with or without psychosocial treatment methods. However, some scholars use MAT to refer to the combination of these medications with psychosocial treatment methods.
}

Matusow et al., 2013; Sharma et al., 2016).

To date, few studies have examined the attitudes towards MAT or referral practices of criminal justice personnel working in court settings (i.e. judges and their staff), with most studies focusing on the attitudes and practices of prison and jail administrators (Chandler, Fletcher, \& Volkow, 2009; Lee et al., 2016; Ludwig \& Peters, 2014; Matusow et al., 2013). Yet court personnel influence whether or not an individual who lives in the community but participates in problem-solving courts, pretrial diversion, or probation may access MAT (Andraka-Christou, 2017; Matusow et al., 2013).

A previous study found that court personnel's attitudes towards MAT strongly predict whether participants may access MAT (Matusow et al., 2013). Specifically, court personnel's attitudes about the following are strong predictors of MAT availability in adult drug courts: MAT efficacy in preventing relapse, MAT effectiveness relative to psychosocial treatments, and maintenance MAT (use over an extended period) (Matusow et al., 2013). Therefore, researchers and policy makers need more information about court personnel's attitudes towards MAT and potential influences on these attitudes. Additionally, little is known regarding whether and how previous education and training about MAT influences attitudes towards MAT. Such information could inform policy initiatives to expand MAT access.

The largest study of court personnel's attitudes towards MAT was published by Matusow et al. in 2013, using data obtained in 2010 (Matusow et al., 2013). In a national sample of over 100 adult drug court personnel, the study found widespread uncertainty and negative attitudes towards methadone and buprenorphine, with $10 \%$ of court staff viewing MAT as a "reward" for criminal behavior (Matusow et al., 2013). The study also found that up to $50 \%$ of adult drug courts nationally prohibited program enrollee use of methadone or buprenorphine for reasons ranging from concerns about efficacy and diversion to cost and lack of providers (Matusow et al., 2013). In a 2017 report of drug court practices in three states, the organization Physicians for Human Rights stated that non-medical personnel routinely prohibited MAT and made medical decisions best left to medical personnel (Neither Justice Nor Treatment Drug Courts in the United States, 2017). The National Association of Drug Court Professionals (NADCP), a nonprofit organization that issues non-binding best practice standards for drug courts, stated that individuals who are legally prescribed "addiction medication" should be eligible to participate in drug court programs (Adult Drug Court Best Practice Standards, 2018). Moreover, the organization passed a unanimous resolution directing drug courts to "learn the facts about MAT" (Adult Drug Court Best Practice Standards, 2018). Additionally, under the Obama Administration, SAMHSA passed a resolution prohibiting federal funding for drug courts that fail to permit MAT (Davies, 2015). However, a previous qualitative study of Indiana drug court judges reported that judges felt the policy had limited effect, because they primarily received state and local funding for drug courts (Andraka-Christou, 2017).

The Matusow et al. study focused exclusively on adult drug court personnel and predated publication of the NADCP standards described above (Adult Drug Court Best Practice Standards, 2018; Matusow et al., 2013). The study did not examine attitudes of personnel in other types of problem-solving courts (e.g., veterans courts and family courts), nor did the study examine attitudes of personnel in non-problem-solving courts (e.g. felony courts and misdemeanor courts.) Problem-solving courts other than adult drug courts have participants with OUD, and these courts can require and monitor treatment for OUD. Data is not available regarding the percentage of other problem-solving courts' participants who have OUD; however, state court system directors, including chief justices, have urged all problem-solving courts to expand OUD treatment interventions in response to the ongoing opioid crisis (Pariente, n.d.). Additionally, many non-problem-solving courts have pretrial diversion programs in which people charged with substance use disorder-related crimes may have their charges dropped upon successful completion of substance use disorder treatment (Pretrial 
Diversion, n.d.). Information about personnel's attitudes in other types of courts would allow researchers and policymakers to design educational initiatives for personnel outside of adult drug courts. Designing education for a broader audience is important given that drug court staff may differ in knowledge and attitudes from staff in other courts.

In addition, the Matusow et al. study did not examine attitudes related to extended-release naltrexone (Matusow et al., 2013), which is an antagonist, meaning it blocks opioid receptors in the brain. In contrast, oral buprenorphine and methadone are agonists, meaning they activate opioid receptors in the brain. Therefore, court personnel concerns related to diversion and misuse may be lower for extended-release naltrexone. On the other hand, relative to agonist treatments (i.e. methadone and buprenorphine), fewer studies exist assessing extendedrelease naltrexone's efficacy for OUD; therefore, it is possible that court personnel believe extended-release naltrexone is less efficacious than agonist treatments. Finally, the Matusow et al. study did not examine the relationship between previous MAT education/training and attitudes towards MAT (Matusow et al., 2013).

Considering the growing opioid overdose problem, a more recent study of MAT attitudes in court settings is critically needed, including settings beyond adult drug courts. To help address this gap, we modified the survey of Matusow et al. (Matusow et al., 2013) and implemented it in Indiana in 2018 with the goal of ascertaining court personnel's attitudes towards methadone, oral buprenorphine, and extended-release naltrexone. Additionally, our study aimed to ascertain any relationship between previous formal MAT education or training in court personnel's professional capacity and attitudes towards MAT. Education could help dispel some of common myths about MAT, such as that it is "just another drug," thereby impacting attitudes towards MAT.

Finally, we aimed to identify associations between demographic variables and attitudes towards MAT. For example, we probed associations between court personnel's gender and attitudes, because a systematic review of gender differences in attitudes towards mental health treatment found that women are more likely to endorse psychosocial conceptions of mental illness and that women tend to view treatment outcomes more favorably (Holzinger, Floris, Schomerus, Carta, \& Angermeyer, 2012). We also aimed to identify any associations between rurality and attitudes, because a previous study found that fewer SAMHSA-waivered physicians exist in rural areas(Rosenblatt, Andrilla, Catlin, \& Larson, 2015); and the presence of a SAMHSAwaivered physician may mediate criminal justice personnel's attitudes towards buprenorphine. Additionally, Matusow et al. previously found that rurality was associated with some negative attitudes towards buprenorphine and methadone (Matusow et al., 2013).

We recruited court personnel who were registered for a statewide MAT education summit for completion of our survey prior to the beginning of the summit. While these results may not be generalizable outside of Indiana and it is unclear how representative the attitudes are of court personnel throughout the state, we believe the results can inform researchers' and Indiana state policy makers' proposed policies for expanding MAT access in court settings, including informational initiatives about MAT.

\section{Methods \& materials}

We modified Matusow et al.'s instrument (Matusow et al., 2013), creating a brief, anonymous survey to explore court professionals' attitudes towards MAT. See the Appendix. The survey was fielded in Indiana in July 2018, and collected information about court professionals' demographics, attitudes towards MAT, and previous MAT education. Prior to launching the survey, we pilot-tested it with three problemsolving court judges in Indiana using a cognitive interviewing process (Willis, 1999, 2005) and modified questions based on their feedback.

\subsection{Participant recruitment}

We recruited a convenience sample from registered participants of the Indiana Statewide Opioid Summit, a special event in July 2018 sponsored by the Indiana Supreme Court, Indiana Family and Social Services Agency, the Association of Indiana Counties, and Indiana University. The summit topic was "A Medication-Assisted Treatment and Addictions Primer for Justice Professionals." We provided a link to the online survey to summit organizers, who then emailed the link to the 947 individuals registered for the summit. The summit's primary audience were employees in the state court and criminal justice systems, including judges, probation officers, law enforcement officers, health care practitioners, defense attorneys, prosecutors, and others. Participants were not provided an incentive for participation in the survey.

\subsection{Data collected}

\subsubsection{Role in the court}

We collected information from respondents about their role in the court. Respondents could choose from the following options: case manager, defense attorney, Department of Child Services attorney, judge, law enforcement officer, mental health/substance use disorder counselor (bachelor's degree), mental health/substance use disorder counselor (master's degree or higher), physician, probation officer, prosecutor, problem-solving court director, or other. Respondents could also choose not to disclose their role.

\subsubsection{Demographics}

We collected demographic information from respondents, including age, gender, educational attainment, and whether they were employed in an urban or rural county. While attendees at the summit came from court programs in all 92 Indiana counties, due to justice professionals' concerns about anonymity, we did not attempt to link respondents' responses to specific geographic areas. We also asked whether the respondent or a close family member was in recovery for a substance use disorder. Respondents could also choose not to disclose demographic data.

\subsubsection{MAT Attitudes}

Our survey included eight statements about each medication (methadone, oral buprenorphine, and extended-release naltrexone), which respondents were asked to rate on a five-point Likert scale that ranged from "strongly disagree" (1) to "strongly agree" (5) (see Tables 2 and 3 for statements about MAT attitudes reported in this article). These questions about MAT attitudes were modified from Matusow et al.'s, 2013 survey (Matusow et al., 2013).

We did not include statements about extended-release buprenorphine formulations (injectable or implantable) given their very recent FDA approvals. We also did not include statements about oral naltrexone, given its limited efficacy due to low adherence rates (Kjome \& Moeller, 2011; Sullivan et al., 2018). Respondents could choose not to answer questions about MAT. Even though the Matusow et al. study used a three-point scale, we used a five-point scale, believing it would better allow us to discriminate between measures.

\subsubsection{Previous Education about MAT}

We asked respondents, "Have you previously received any formal education or training about medication-assisted treatment in your capacity as a court employee?" Respondents could also choose not to disclose whether they had previously received education or training about MAT.

The survey was implemented in Qualtrics software. The study was approved by the Indiana University Human Subjects Institutional Review Board. 


\subsection{Analysis}

Descriptive statistics were explored to capture the demographic information for survey respondents. Differences between respondents' attitudes towards MAT were explored using bivariate statistics. Analyses of variance (ANOVA) were used to analyze average differences in attitudes across the three MAT treatment categories. $T$-Tests were used to compare the difference between average attitudes between certain key demographic groups, including gender, rurality, and whether the court personnel had previously received formal MAT education or training. Multivariate linear regression was used to analyze the associations between respondents' demographic characteristics and their attitudes towards MAT treatments. All statistical analyses were conducted using SAS Enterprise Guide 9.4.

Due to a limited number of respondents in some categories of justice professionals, for purposes of analysis we combined the following personnel: judges and problem-solving court program director (due to their leadership roles in court programs); law enforcement officers and prosecutors (due their law enforcement background); and mental health/substance use counselor with a bachelor's degree, mental health/substance use counselor with a master's degree or higher, case managers, and physicians (due to their health care focus). Probation officers and corrections officials were combined due to their background in corrections. The "other" category included defense attorneys, Department of Children Services attorneys, and respondents who either identified as "other" or did not state their professions. Other groupings of court personnel were explored, and findings were robust to these sensitivity analyses.

For purposes of data analysis and presentation, we reverse-coded some of the Likert scale items, a process commonly followed in survey data analysis (Józsa \& Morgan, 2017), so that a high value indicates the same type of response (e.g. a positive attitude) to every item. Specifically, for any statements that presented a substance negatively (e.g. "methadone does not reduce or block the effects of heroin; $1=$ strong disagreement and $5=$ strong agreement), we reverse-coded those statements and associated Likert scale items to present the substance positively (e.g. methadone reduces or blocks the effects of heroin; $1=$ strong agreement and $5=$ strong disagreement). In total, we reverse-coded three statements: "substance rewards criminals for being drug users," "substance prolongs addiction," and "substance interferes with one's ability to drive a car."

\section{Results}

We collected data from 235 justice personnel in Indiana who had registered for the MAT education summit. For purposes of analysis, we excluded data from four respondents who completed the survey after the summit had begun, in case summit participation influenced attitudes. Therefore, our final sample included data from 231 respondents (a $24 \%$ response rate), all of whom provided responses prior to the beginning of the summit.

\subsection{Respondent characteristics}

\subsubsection{Demographic data}

Approximately half of the respondents disclosed they were female $(46 \% ; n=104)$ and more than one-third disclosed they were male ( $39 \% ; n=89)$; the remainder did not disclose their gender. More than half indicated they worked in a rural county $(58 \% ; n=134)$, while a quarter worked in an urban county $(25 \% ; n=56)$, with the remainder not disclosing. One quarter stated that they or a close family member were in recovery from a substance use disorder $(21 \% ; n=48)$; almost three quarters stated that neither they nor a close family member were in recovery $(62 \% ; n=143)$, with a few choosing not to disclose. About half were younger than 50 years old $(48 \% ; n=110)$, more than a third were older than 50 years old $(36 \% ; n=84)$, with the remainder not
Table 1

Descriptive statistics for court personnel.

\begin{tabular}{|c|c|c|}
\hline Characteristics of respondents & $\mathrm{N}$ & $\%$ \\
\hline Gender: female & 104 & $46 \%$ \\
\hline Gender: male & 89 & $39 \%$ \\
\hline Prefer not to disclose & 38 & $17 \%$ \\
\hline Court: rural Area & 133 & $58 \%$ \\
\hline Court: urban Area & 56 & $25 \%$ \\
\hline Prefer not to disclose & 42 & $19 \%$ \\
\hline Age: $18-29$ & 6 & $3 \%$ \\
\hline Age: $30-49$ & 104 & $45 \%$ \\
\hline Age: $50-64$ & 75 & $32 \%$ \\
\hline Age: $65+$ & 9 & $4 \%$ \\
\hline Prefer not to disclose & 37 & $16 \%$ \\
\hline Case manager & 6 & $3 \%$ \\
\hline Defense attorney & 11 & $5 \%$ \\
\hline Department of Child Services attorney & 3 & $1 \%$ \\
\hline Judge & 43 & $18 \%$ \\
\hline Law enforcement officer & 18 & $8 \%$ \\
\hline Mental health/SUD counselor - bachelor's Degree & 2 & $1 \%$ \\
\hline Mental health/SUD counselor - master's Degree Higher & 15 & $6 \%$ \\
\hline Other & 55 & $23 \%$ \\
\hline Physician (MD) & 2 & $1 \%$ \\
\hline Probation officer & 44 & $19 \%$ \\
\hline Problem-solving court director/coordinator & 7 & $3 \%$ \\
\hline Prosecutor & 16 & $7 \%$ \\
\hline Prefer not to disclose & 9 & $4 \%$ \\
\hline Associate degree & 3 & $1 \%$ \\
\hline Bachelor's degree & 58 & $25 \%$ \\
\hline Graduate or professional degree & 116 & $50 \%$ \\
\hline High school graduate & 1 & $0 \%$ \\
\hline Some college & 6 & $3 \%$ \\
\hline Some graduate work & 8 & $3 \%$ \\
\hline Trade/technical/vocational training & 2 & $1 \%$ \\
\hline Prefer not to disclose & 37 & $16 \%$ \\
\hline No: You or a close family member are in recovery & 143 & $62 \%$ \\
\hline Yes: You or a close family member are in recovery & 48 & $21 \%$ \\
\hline Prefer not to disclose & 40 & $17 \%$ \\
\hline No previous formal MAT education/training & 93 & $40 \%$ \\
\hline Previous formal MAT education/training & 103 & $45 \%$ \\
\hline Prefer not to disclose & 35 & $15 \%$ \\
\hline
\end{tabular}

MAT $=$ medication-assisted treatment SUD $=$ substance use disorder.

disclosing their age. More than half of respondents had a graduate degree $(50 \% ; n=116)$; a quarter had a bachelor's degree $(25 \%$; $n=58)$; and only $8 \%(n=20)$ had neither a bachelor's nor a graduate degree; the remainder did not disclose their education completion. See Table 1.

\subsubsection{Previous formal MAT education or training in capacity as court employee}

Slightly more respondents had received formal MAT education or training in their capacity as a court employee prior to the summit (45\%; $n=103)$ as compared to those who had not $(40 \% ; n=93)$, with the remainder choosing not to disclose.

\subsubsection{Professional role in the court}

The most common professional roles in the court were "other" $(23 \% ; n=55)$, probation officers $(19 \% ; n=44)$, and judges $(18 \%$; $n=43)$. About one-tenth $(10 \% ; n=25)$ were healthcare professionals, such as a mental health SUD/counselor, physician, or case manager. Less common were law enforcement officers $(8 \% ; n=18)$, prosecutors $(7 \% ; n=16)$, defense attorneys $(5 \%, n=11)$, problem-solving court directors ( $3 \% ; n=7)$, and Department of Child Services attorneys $(n=3 ; 1 \%)$. A few $(4 \% ; n=9)$ chose not to disclose their role in the court.

\subsection{Attitudes towards MAT}

Of the 231 respondents who submitted survey responses, 192 respondents answered all questions about MAT attitudes (see Tables 2 
Table 2

Average attitudes about medication-assisted treatments.

\begin{tabular}{|c|c|c|c|c|}
\hline Questions about attitudes & Methadone & Buprenorphine & Vivitrol & Sig. ANOVA \\
\hline SUBSTANCE reduces relapse & 3.2 & 3.46 & 3.97 & $p<0.001$ \\
\hline SUBSTANCE reduces crime and re-incarceration & 2.85 & 3.03 & 3.67 & $\mathrm{p}<0.001$ \\
\hline SUBSTANCE does not reward criminals for being drug users & 3.56 & 3.54 & 3.94 & $\mathrm{p}<0.001$ \\
\hline SUBSTANCE does not prolong addiction & 2.51 & 2.70 & 3.58 & $\mathrm{p}<0.001$ \\
\hline SUBSTANCE should be used to maintain clients who have OUD & 3 & 3.40 & 3.88 & $\mathrm{p}<0.001$ \\
\hline SUBSTANCE is more effective than non-pharmacological approaches to retaining clients in treatment & 3.08 & 3.25 & 3.80 & $\mathrm{p}<0.001$ \\
\hline SUBSTANCE does not interfere with one's ability to drive a car & 2.72 & 2.99 & 3.71 & $\mathrm{p}<0.001$ \\
\hline \multirow[t]{2}{*}{ SUBSTANCE reduces or blocks the effect of heroin } & 3.12 & 3.41 & 3.98 & $\mathrm{p}<0.001$ \\
\hline & $\operatorname{Avg}=3.00$ & $\operatorname{Avg}=3.22$ & $\operatorname{Avg}=3.82$ & \\
\hline
\end{tabular}

OUD $=$ opioid use disorder.

Table 3

Attitudes about medication-assisted treatments.

\begin{tabular}{|c|c|c|c|c|c|}
\hline & $\% \mathrm{SD}$ & $\% \mathrm{D}$ & $\%$ Neutral/Unsure & $\% \mathrm{~A}$ & $\%$ SA \\
\hline \multicolumn{6}{|l|}{ Methadone } \\
\hline Methadone reduces relapse & 14 & 16 & 18 & 38 & 13 \\
\hline Methadone reduces crime and re-incarceration & 20 & 20 & 26 & 24 & 10 \\
\hline Methadone does not reward criminals for being drug users & 5 & 17 & 23 & 24 & 30 \\
\hline Methadone does not prolong addiction & 26 & 33 & 16 & 14 & 11 \\
\hline Methadone should be used to maintain clients who have OUD & 12 & 22 & 30 & 25 & 11 \\
\hline Methadone is more effective than non-pharmacological approaches to retaining clients in treatment & 8 & 19 & 38 & 26 & 9 \\
\hline Methadone does not interfere with one's ability to drive a car & 15 & 23 & 44 & 12 & 6 \\
\hline Methadone reduces or blocks the effect of heroin & 14 & 13 & 34 & 24 & 15 \\
\hline \multicolumn{6}{|l|}{ Oral Buprenorphine } \\
\hline Oral buprenorphine reduces relapse & 8 & 15 & 18 & 43 & 16 \\
\hline Oral buprenorphine reduces crime and re-incarceration & 16 & 18 & 24 & 32 & 11 \\
\hline Oral buprenorphine does not reward criminals for being drug users & 4 & 14 & 31 & 25 & 26 \\
\hline Oral buprenorphine does not prolong addiction & 17 & 32 & 24 & 18 & 9 \\
\hline Oral buprenorphine should be used to maintain clients who have OUD & 7 & 12 & 28 & 40 & 13 \\
\hline Oral buprenorphine is more effective than non-pharmacological approaches to retaining clients in treatment & 6 & 16 & 38 & 30 & 11 \\
\hline Oral buprenorphine does not interfere with one's ability to drive a car & 8 & 21 & 46 & 15 & 11 \\
\hline Oral buprenorphine reduces or blocks the effect of heroin & 6 & 12 & 35 & 29 & 18 \\
\hline \multicolumn{6}{|l|}{ Extended-Release Naltrexone } \\
\hline & 2 & 5 & 23 & 37 & 34 \\
\hline Extended-release naltrexone reduces crime and re-incarceration & 5 & 4 & 31 & 38 & 22 \\
\hline Extended-release naltrexone does not reward criminals for being drug users & 2 & 5 & 32 & 19 & 42 \\
\hline Extended-release naltrexone does not prolong addiction & 4 & 9 & 40 & 21 & 27 \\
\hline Extended-release naltrexone should be used to maintain clients who have OUD & 2 & 4 & 32 & 30 & 32 \\
\hline Extended-release naltrexone is more effective than non-pharmacological approaches to retaining clients in treatment & 2 & 4 & 36 & 32 & 27 \\
\hline Extended-release naltrexone does not interfere with one's ability to drive a car & 1 & 3 & 52 & 12 & 32 \\
\hline Extended-release naltrexone reduces or blocks the effect of heroin & 1 & 3 & 34 & 22 & 41 \\
\hline
\end{tabular}

SD = Strongly Disagree, $\mathrm{D}=$ Somewhat Disagree, $\mathrm{A}=$ Somewhat Agree, SA = Strongly Agree; OUD = opioid use disorder

and 3 for detailed responses).

Across all questions regarding MAT attitudes, respondents had significantly more negative attitude towards methadone than oral buprenorphine, and significantly more negative attitudes towards oral buprenorphine than extended-release naltrexone. See Tables 2 and 3.

On average, court personnel did not choose a 4 or 5 on the Likert scale (indicating "somewhat agree" or "strongly agree") with positive statements about any of the medications. Average agreement with positive statements about the substances on a scale of $1-5$ were as follows: 3.00 for methadone; 3.22 for oral buprenorphine, and 3.82 for extended-release naltrexone.

Sixty-one percent agreed or strongly agreed with the statement "extended-release naltrexone does not reward criminals for being drug users." In contrast, approximately half (54\%) agreed or strongly agreed with the statement "methadone does not reward criminals for being drug users," and half (51\%) agreed or strongly agreed with the statement "oral buprenorphine does not reward criminals for being drug users."

Forty-eight percent agreed or strongly agreed with the statement "extended-release naltrexone does not prolong addiction." In contrast, only (27\%) agreed or strongly agreed with the statement "buprenorphine does not prolong addiction," and a quarter (25\%) agreed or strongly agreed with the statement "methadone does not prolong addiction." See Table 3 for level of agreement with other statements about the medications.

More than half of our sample believed that methadone and buprenorphine prevent relapse (51\% for methadone; $59 \%$ for buprenorphine;). Almost two-thirds believed that extended-release naltrexone prevents relapse $(71 \%)$ and should be used to maintain clients with OUD $(62 \%)$. More than a third of our sample believed that clients should be maintained on methadone (36\%), and more than half (53\%) believed that clients should be maintained on buprenorphine.

About a third of our sample believed that methadone is more effective than non-pharmacological approaches to treatment and that buprenorphine is more effective than non-pharmacological approaches ( $35 \%$ and $41 \%$, respectively). Over half $(59 \%)$ of our sample believed that extended-release naltrexone is more effective than non-pharmacological approaches.

\subsection{Bivariate relationships between respondents' attitudes and other variables}

We compared the average attitudes towards MAT between key demographic groupings (see Table 4). We found that average attitudes did 
Table 4

Multivariate regression analyses.

\begin{tabular}{|c|c|c|c|c|c|c|}
\hline \multirow[t]{2}{*}{ Covariates } & \multicolumn{2}{|c|}{ Average Attitudes About Methadone } & \multicolumn{2}{|c|}{$\begin{array}{l}\text { Average Attitudes about Oral } \\
\text { Buprenorphine }\end{array}$} & \multicolumn{2}{|c|}{$\begin{array}{l}\text { Average Attitudes about Extended-Release } \\
\text { Naltrexone }\end{array}$} \\
\hline & Estimate & Sig. & Estimate & Sig. & Estimate & Sig. \\
\hline Female & -0.06711 & 0.565 & -0.01777 & 0.8745 & 0.12436 & 0.1763 \\
\hline Male & ref & & ref & & ref & \\
\hline 18-29 Years & ref & & ref & & ref & \\
\hline 30-49 Years & -0.21601 & 0.4784 & -0.24603 & 0.4031 & -0.04405 & 0.8541 \\
\hline 50-64 Years & -0.25569 & 0.41 & -0.35565 & 0.2357 & -0.08507 & 0.7273 \\
\hline $65+$ Years & 0.24628 & 0.5406 & -0.02794 & 0.9426 & -0.079 & 0.8029 \\
\hline Less than a college degree & -0.45953 & 0.0822 & -0.2469 & 0.3319 & -0.41565 & $0.046^{*}$ \\
\hline Bachelor's degree & -0.23724 & 0.0804 & -0.18667 & 0.1535 & -0.21352 & 0.0458 \\
\hline Graduate or professional degree & ref & & ref & & ref & \\
\hline You or close family member are in recovery & 0.13428 & 0.2978 & 0.07956 & 0.5224 & 0.14787 & 0.1457 \\
\hline $\begin{array}{l}\text { Neither you nor a close family member are in } \\
\text { recovery }\end{array}$ & ref & & ref & & ref & \\
\hline $\begin{array}{l}\text { Prefer not to disclose if you or close family } \\
\text { member are in recovery }\end{array}$ & -0.61522 & 0.1465 & -0.215 & 0.5981 & -0.17774 & 0.5929 \\
\hline Urban & ref & & ref & & ref & \\
\hline Rural & -0.14224 & 0.2338 & -0.18324 & 0.1127 & -0.16276 & $0.0841^{*}$ \\
\hline $\begin{array}{l}\text { No previous formal MAT education/training in } \\
\text { capacity as court employee }\end{array}$ & ref & & ref & & ref & \\
\hline $\begin{array}{l}\text { Previous formal MAT education/training in } \\
\text { capacity as court employee }\end{array}$ & 0.22763 & $0.0407^{*}$ & 0.23416 & 0.0293 & 0.45996 & $<0.0001^{*}$ \\
\hline Corrections & 0.28063 & 0.1652 & 0.54809 & 0.0054 & -0.01369 & 0.9313 \\
\hline Judge & -0.24873 & 0.1619 & -0.06335 & 0.7114 & -0.10608 & 0.4474 \\
\hline Law Enforcement & -0.40444 & 0.0418 & -0.52925 & $0.0061^{*}$ & -0.04109 & 0.7915 \\
\hline Other & 0.19096 & 0.2447 & 0.15189 & 0.3375 & -0.14178 & 0.2722 \\
\hline Healthcare & ref & & ref & & ref & \\
\hline
\end{tabular}

MAT $=$ medication-assisted treatment.

* Items in bold were statistically significant at $\mathrm{p}<0.05$.

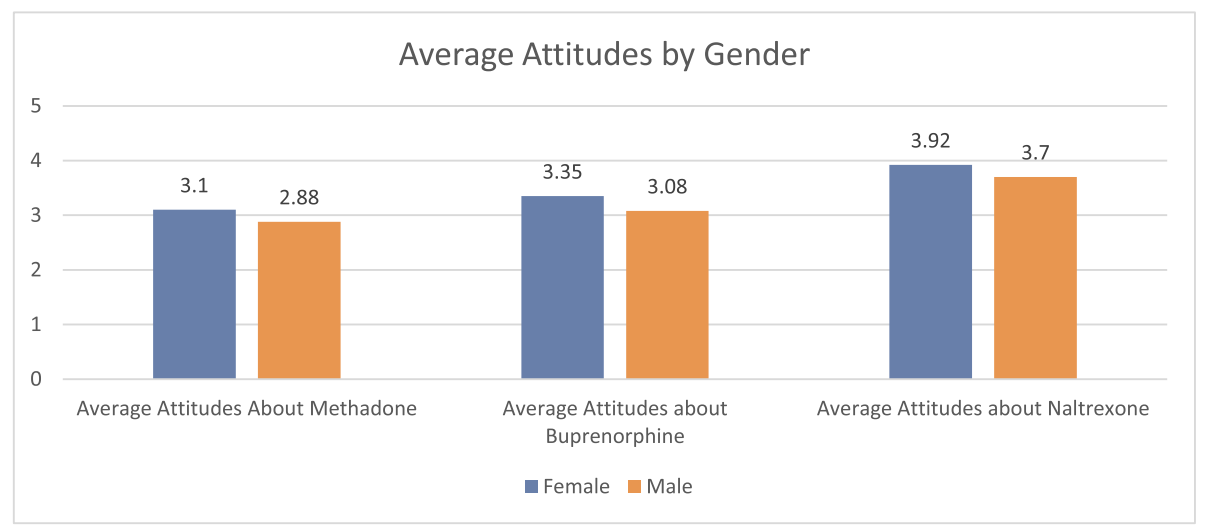

Fig. 1. Average Attitudes by Gender.

Not significantly different from each other $p<0.05$.

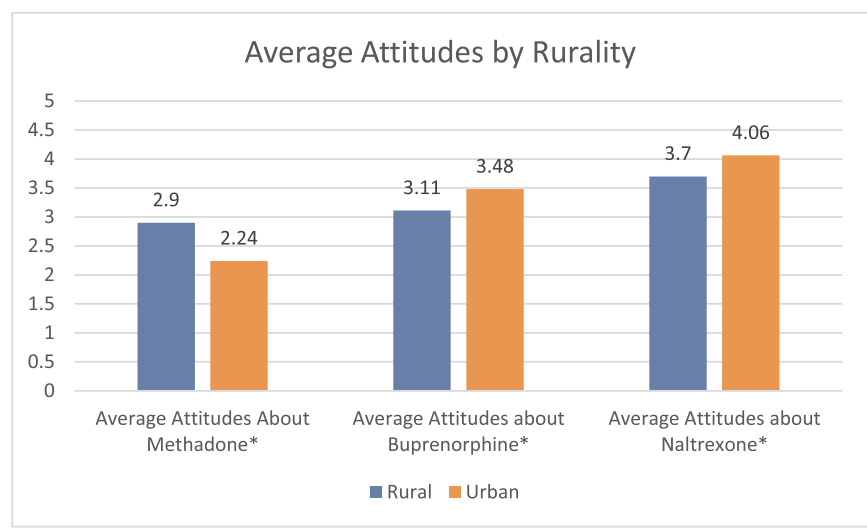

Fig. 2. Average Attitudes by Rurality.

*significantly different from each other $\mathrm{p}<0.05$. not differ significantly by gender for any MAT treatment $(P>0.05)$. When we explored the bivariate relationship between average attitudes by rurality, we found that respondents that worked in courts in rural counties had significantly more negative attitudes towards MAT than those working in urban areas $(p<0.05)$. Average attitudes were also significantly different based on whether respondents had received formal MAT education or training prior to the summit in their capacity as a court employee. Average attitudes for methadone were 2.84 on a five-point Likert scale for those without formal MAT education or training compared with 3.15 for those with formal MAT education or training $(p<0.05)$. When average attitudes towards oral buprenorphine were compared across these two categories, we found that attitudes were significantly different, with 3.05 for those without previous formal MAT education or training and 3.38 for those with previous formal MAT education or training $(p<0.05)$. Average attitudes were also different for extended-release naltrexone across groups, with 3.49 for those without previous formal MAT education or training and 4.1 
for those with formal MAT education or training ( $p<0.05$ ). See Figures 1 and 2.

\subsection{Multivariate relationships between respondents' attitudes and other variables}

Below we report relationships between respondents' attitudes towards MAT and other variables, including gender, age, educational attainment, whether they had a close family in recovery, rurality, previous formal MAT education or training, and role in the court. See Table 4.

After controlling for the above characteristics, gender was not significantly associated with respondents' attitudes towards any of the medications. Also, after controlling for other variables, rural or urban locations were not significantly associated with attitudes towards any of the medications. When compared to those with graduate education, respondents without graduate education had significantly more negative attitudes towards extended-release naltrexone; this finding was not significant for average attitudes about methadone oral buprenorphine.

Previous formal education or training about MAT in one's capacity as a court employee was significantly associated with more positive attitudes towards all medications. Previous MAT education or training was associated with attitudes towards methadone and oral buprenorphine that were a quarter of a point more positive, and attitudes towards extended-release naltrexone that were nearly half a point more positive.

Roles in the court were explored in the multivariate regression analyses, and law enforcement officers and prosecutors had significantly lower attitudes towards methadone and oral buprenorphine than did other court personnel $(p<0.05)$. No significant differences in attitudes were found towards extended-release naltrexone. See Figure 3.

\section{Discussion}

The goal of our study was to explore attitudes towards MAT among criminal justice professionals working in Indiana courts, including judges, law enforcement officers, probation officers, prosecutors, law enforcement officers, and healthcare providers. We compared attitudes across different types of professionals and compared attitudes towards different types of OUD medications (methadone, oral buprenorphine, and extended-release naltrexone). We also examined associations between attitudes and previous formal MAT education or training, as well as attitudes and demographic variables. Our survey was based on the survey by Matusow et al. (Matusow et al., 2013) with the addition of questions about previous formal MAT education or training in the role of court employee and questions about extended-release naltrexone.

As compared to the nationally representative sample in the Matusow et al. study, our sample had more respondents; however, our sample was one of convenience (participants attending an education summit) and limited to Indiana. Additionally, our respondents were registered for a statewide educational summit about MAT, so they may have had more interest in or preexisting knowledge about MAT relative to respondents in Matusow et al.'s sample and other court personnel in Indiana. Unlike the Matusow et al. study, our sample included personnel working in courts other than adult drug courts (e.g. veterans' courts, family courts, felony courts, misdemeanor courts).

In our sample, some respondents' attitudes were more negative than those expressed by respondents in the Matusow et al. sample. For example, a larger proportion of our sample felt that buprenorphine rewarded criminals ( $18 \%$ versus $10 \%$ in the Matusow et al. study). Also, a much larger proportion of our sample believed that buprenorphine prolongs addiction (49\% versus $21 \%$ ) and that methadone prolongs addiction (59\% versus $38 \%$ ). Interestingly, only $7 \%$ of respondents in our sample believed that extended-release naltrexone rewarded criminals, and only $13 \%$ of respondents in our sample believed that extended-release naltrexone prolongs addiction. Justice personnel may misperceive methadone and oral buprenorphine as "rewards," because the medications are agonists, meaning they activate the opioid receptors in the brain, even though they do not produce the level of euphoria of the original drug of abuse (Medications to Treat Opioid Use Disorder, 2018). In contrast, extended-release naltrexone is an antagonist, meaning it blocks opioids receptors in the brain and is not associated with any level of euphoria. However, the notion that methadone and buprenorphine "reward" individuals mischaracterizes the role of agonist medications, which by activating opioid receptors prevent cravings and withdrawal symptoms despite their potential for misuse.

Even though certain attitudes that respondents in our study expressed were more negative than those in the Matusow et al. study, our sample held more positive attitudes towards the three measures found by Matusow et al. to be predictive of agonist treatment access in adult drug courts (Matusow et al., 2013). Specifically, our sample had more

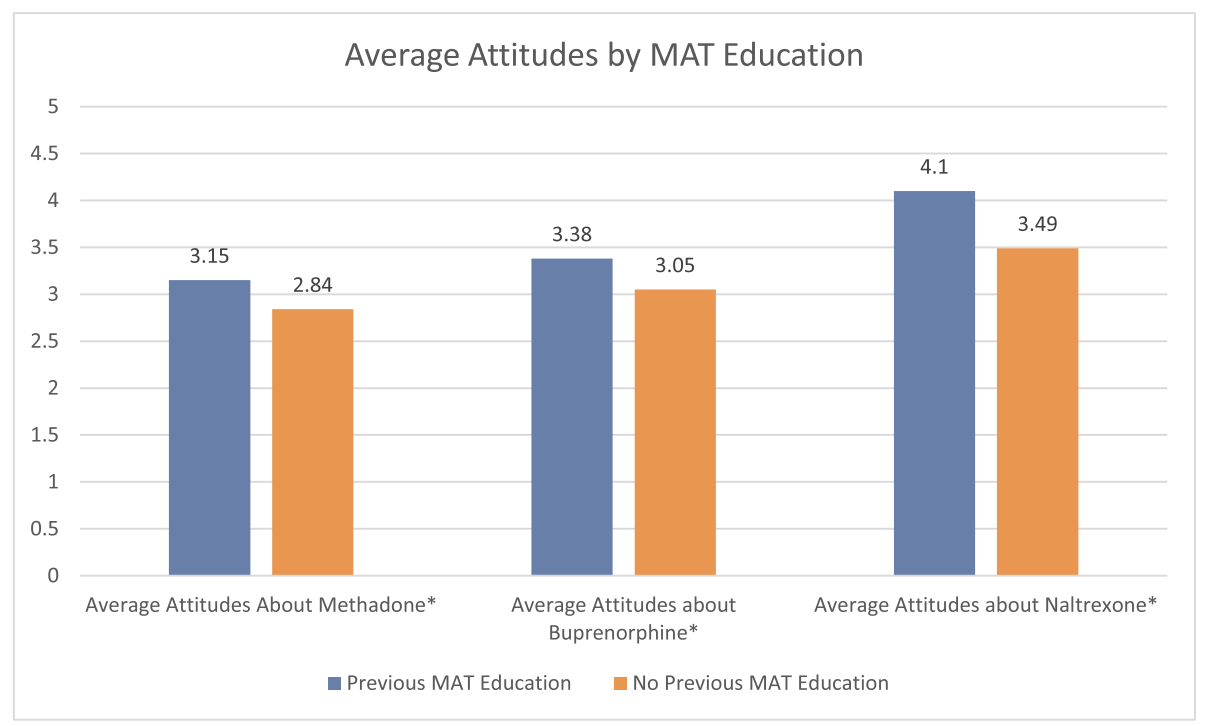

Fig. 3. Average Attitudes by Previous Formal MAT Education/Training in Capacity as Court Employee.

*significantly different from each other $p<0.05$.

MAT $=$ Medication Assisted Treatment. 
positive attitudes towards the efficacy of methadone and buprenorphine in relapse prevention, the efficacy of methadone and buprenorphine relative to non-pharmacological approaches, and the importance of maintaining clients on methadone and buprenorphine. For example, relative to participants in the Matusow et al. sample, our respondents were approximately three times as likely to state that methadone and buprenorphine are more effective than non-pharmacological approaches to treatment (for methadone, $35 \%$ versus $11 \%$; for buprenorphine, $41 \%$ versus $16 \%$ ). Likewise, a larger percentage of respondents in our sample believed that clients should be maintained on methadone (36\% versus $31 \%$ ), and twice as many respondents in our sample believed that clients should be maintained on buprenorphine (53\% versus $26 \%$ ). Finally, a larger percentage of respondents in our sample believed that methadone and buprenorphine prevent relapse ( $51 \%$ versus $44 \%$ for methadone; and $59 \%$ versus $45 \%$ for buprenorphine).

These more positive beliefs in our sample may reflect greater levels of education about MAT in 2018 relative to 2010 (when the Matusow et al. study was fielded) and an increase in policy initiatives to expand MAT, such as a prohibition of SAMHSA funding for drug courts that ban MAT (Davies, 2015). This interpretation is bolstered by the fact that previous formal MAT education or training in one's capacity as a court employee was found to be predictive of positive beliefs towards all three medications in our study. Alternatively, court personnel in Indiana (particularly those who attended the educational summit) may have more positive attitudes towards these three measures relative to court personnel nationally.

What is particularly striking about our study is the level of positive attitudes towards extended-release naltrexone as compared to methadone and oral buprenorphine. For example, almost three-quarters of our sample believed that extended-release naltrexone prevented relapse (71\%); more than half believed that extended-release naltrexone should be used to maintain clients with OUD (62\%); and more than half (59\%) believed that extended-release naltrexone is more effective than nonpharmacological approaches. In fact, even though more evidence exists for the efficacy of methadone and oral buprenorphine in decreasing opioid misuse and overdose, our respondents had significantly more positive beliefs about extended-release naltrexone overall.

More positive attitudes towards extended-release naltrexone may be explained by historic hostility towards agonist treatments in the criminal justice system (Ludwig \& Peters, 2014; Nunn et al., 2009; Sharma et al., 2016). Such attitudes may be due to the difficulty of finding trustworthy providers, concerns about misuse or diversion, and lack of belief in the medications' efficacy (Andraka-Christou, 2017; Matusow et al., 2013). In contrast, as an antagonist, extended-release naltrexone has no potential for psychotropic effects, and is therefore less likely to be diverted than are agonist medications. Additionally, news reports suggest that the manufacturer of extended-release naltrexone has been targeting advertisements towards drug courts, particularly judges, likely due to knowledge of historic hostility towards agonist treatments in the criminal justice system (Harper, 2017). It is possible that the manufacturer's marketing activities have been more frequent or intense in Indiana relative to other states. News reports that Alkermes' marketing efforts disparaged methadone and buprenorphine prompted Senator Kamala Harris to launch an investigation into Alkermes' marketing practices in 2017 ("Senator Harris Launches Investigation into Pharmaceutical Manufacturer Alkermes Regarding Opioid Addiction Treatment Manipulation,", 2017). However, no peer-reviewed study to date has reviewed the relationship between Alkermes' marketing efforts and court personnel's attitudes. Court personnel may also feel that an opioid-free treatment is more appropriate for clients who have already undergone opioid detoxification (e.g. in jail awaiting trial) as compared to an agonist treatment. Additionally, since methadone may be provided only in opioid treatment programs and oral buprenorphine may be prescribed only by a SAMHSA-waivered provider, respondents may feel that the logistical barriers to criminal justice participants accessing those medications are higher than the barriers to accessing extendedrelease naltrexone; therefore, respondents may feel that extended-release naltrexone is a better choice for criminal justice participants. Even though Matusow et al. did not include questions about extended-release naltrexone in their study, they did find that logistical barriers (such as too few providers in an area) influenced adult drug court personnel's decisions not to allow MAT (Matusow et al., 2013).

More positive attitudes towards naltrexone may also be explained by distrust of local buprenorphine and methadone providers, because a previous qualitative study of Indiana problem-solving court judges found that judges had greater distrust of methadone providers than oral buprenorphine or extended-release naltrexone providers (AndrakaChristou, 2017). In that study, judges felt that methadone providers were either providing overly high dosages or were not properly monitoring participants, both of which amplified judges' fears of methadone diversion and misuse (Andraka-Christou, 2017).

We are not surprised that law enforcement personnel held more negative attitudes about oral buprenorphine and methadone relative to other court personnel. Given their background in criminal justice but not healthcare, they may view agonist medications through a criminal justice lens rather than a healthcare lens. In other words, the potential of agonist diversion and misuse may be more salient to law enforcement than the well-established treatment efficacy of agonist medications.

In our sample, less than half of respondents (45\%) reported having previously received formal education or training about MAT in the respondent's capacity as a court employee. Importantly, previous MAT education/training was significantly associated with positive attitudes towards all the medications, especially extended-release naltrexone. These results suggest that initiatives to increase MAT access should include education for justice personnel working in court settings, especially since courts are even less likely than other criminal justice institutions to refer individuals for MAT (Krawczyk et al., 2017). We did not ask respondents about the method or extent of education received, so we do not know whether such education was obtained from a pharmaceutical company, continuing education course, conference, or independent reading, nor do we know the depth of education provided. For example, it is possible that the previous formal MAT education or training was provided by Alkermes, thus explaining the larger effect of former MAT education or training on attitudes towards extended-release naltrexone than on attitudes towards oral buprenorphine and methadone. Future research should examine the most effective format and provider of MAT education or training for justice personnel.

Our study has several strengths and limitations. We collected information about a range of medications and were thus able to compare attitudes about the three most common forms of MAT, including extended-release naltrexone. By including a wide variety of justice personnel in our sample, we were able to compare beliefs between different types of personnel working in courts, even though we did not identify the type of courts in which they work. Additionally, by including a question about previous formal MAT education or training in the respondent's capacity as a court employee, we were able to identify any potential relationships between MAT education or training and attitudes, a previously underexplored topic.

Because we surveyed only justice personnel who were registered for the educational summit, we are limited in our ability to generalize our results to justice personnel who did not register for the summit. Furthermore, since participants knew the summit focused on MAT ahead of time, those participants who completed the survey may be more likely than others to have a preexisting interest in MAT. If this is true, then our results may overstate justice personnel's positive attitudes and understate negative attitudes about MAT relative to attitudes held by the typical justice personnel in Indiana. Future studies should explore justice personnel's attitudes towards MAT across the U.S. to detect any potential differences based on geographic location. Additionally, future studies should examine differences in attitudes based on the type of court in which the respondent is employed. 


\section{Conclusion}

Criminal justice personnel in our study working in court settings had significantly more negative attitudes towards methadone than oral buprenorphine, and significantly more negative attitudes towards oral buprenorphine than extended-release naltrexone. This result may be explained by historic and current misinformation in the criminal justice system about agonist treatments. Previous formal MAT education or training in the respondent's capacity as a court employee was significantly associated with positive beliefs about all medications, especially extended-release naltrexone, suggesting that informational initiatives should target criminal justice professionals in court settings. Law enforcement officers and prosecutors had significantly more negative attitudes towards methadone and oral buprenorphine than did other court personnel, possibly because they view agonist medications through a criminal justice lens rather than a healthcare lens; in other words, the potential of agonist diversion and misuse may be more salient to law enforcement than the well-established treatment efficacy of agonists. Our results may not be generalizable to other states; additionally, it is possible that our respondents had more interest in and knowledge about MAT relative to other court personnel in the state, since they were registered for a MAT education summit. Future studies should further examine the type of MAT education that justice personnel receive and the most effective format and provider of such education.

\section{Funding}

No funding was used to support this research.

\section{Declaration of Competing Interest}

None.

\section{Appendix A}

\section{MEDICATION-ASSISTED TREATMENT INDIANA COURT SURVEY}

[Questions marked with an asterisk differ from those in Matusow et al.'s, 2013 survey or did not appear in their survey]. INTRODUCTION

1. What is your profession?*

- Judge

- Probation officers

- Law enforcement officers

- Mental health/SUD counselor-bachelor's degree

- Mental health/SUD counselor-Master's degree or higher

- Defense attorney

- Prosecutor

- Drug Court Services (DCS) Attorney

- Physician (MD)

- Veterans Administration liaison

- Case manager

- Program director/court program coordinator

- Other

\section{COURT POLICIES}

[Only judges received questions about court policies, so they are not reported in this manuscript].

ATTITUDES AND KNOWLEDGE ABOUT MAT

[Matusow et al.'s survey provided three answer choices: disagree, agree, and unsure]

2. To what extent do you agree with the statements below about methadone.

\begin{tabular}{|c|c|c|c|c|c|c|}
\hline & $\begin{array}{l}\text { Strongly dis- } \\
\text { agree }\end{array}$ & $\begin{array}{l}\text { Somewhat dis- } \\
\text { agree }\end{array}$ & $\begin{array}{l}\text { Neither agree nor } \\
\text { disagree }\end{array}$ & $\begin{array}{l}\text { Somewhat } \\
\text { agree }\end{array}$ & $\begin{array}{l}\text { Strongly } \\
\text { agree }\end{array}$ & Unsure \\
\hline \multicolumn{7}{|l|}{ Methadone reduces relapse } \\
\hline \multicolumn{7}{|l|}{ Methadone reduces crime and re-incarceration } \\
\hline \multicolumn{7}{|l|}{ Methadone rewards criminals for being drug users } \\
\hline \multicolumn{7}{|l|}{ Methadone prolongs addiction } \\
\hline \multicolumn{7}{|c|}{$\begin{array}{l}\text { Methadone should be used to maintain clients who have opioid use dis- } \\
\text { order }\end{array}$} \\
\hline \multicolumn{7}{|c|}{$\begin{array}{l}\text { Methadone is more effective than non-pharmacological approaches to } \mathrm{r} \text { - } \\
\text { etaining clients in treatment }\end{array}$} \\
\hline \multicolumn{7}{|c|}{ Methadone interferes with one's ability to drive a car } \\
\hline Methadone reduces or blocks the effect of heroin & & & & & & \\
\hline
\end{tabular}

3. To what extent do you agree with the statements below about buprenorphine (e.g. Suboxone).

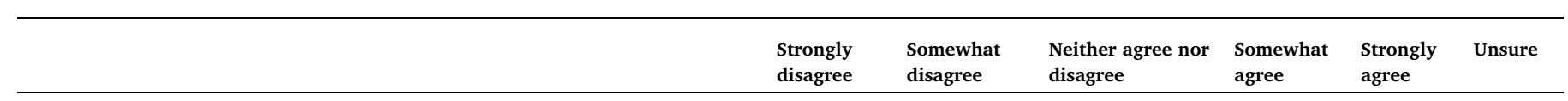

Buprenorphine (e.g. Suboxone) reduces relapse

Buprenorphine (e.g. Suboxone) reduces crime and re-incarceration 
Buprenorphine (e.g. Suboxone) rewards criminals for being drug users

Buprenorphine (e.g. Suboxone) prolongs addiction

Buprenorphine (e.g. Suboxone) should be used to maintain clients who have opioid use disorder

Buprenorphine (e.g. Suboxone) is more effective than non-pharmacological approaches to retaining clients in treatment

Buprenorphine (e.g. Suboxone) interferes with one's ability to drive a car

Buprenorphine (e.g. Suboxone) reduces or blocks the effect of heroin

4. To what extent do you agree with the statements below about extended-release naltrexone (Vivitrol)*

\begin{tabular}{|c|c|c|c|c|c|c|}
\hline & $\begin{array}{l}\text { Strongly } \\
\text { disagree }\end{array}$ & $\begin{array}{l}\text { Somewhat } \\
\text { disagree }\end{array}$ & $\begin{array}{l}\text { Neither agree nor } \\
\text { disagree }\end{array}$ & $\begin{array}{l}\text { Somewhat } \\
\text { agree }\end{array}$ & $\begin{array}{l}\text { Strongly } \\
\text { agree }\end{array}$ & Unsure \\
\hline \multicolumn{7}{|l|}{ Extended-release naltrexone (Vivitrol) reduces relapse } \\
\hline \multicolumn{7}{|l|}{ Extended-release naltrexone (Vivitrol) reduces crime and re-incarceration } \\
\hline \multicolumn{7}{|l|}{ Extended-release naltrexone (Vivitrol) rewards criminals for being drug users } \\
\hline \multicolumn{7}{|l|}{ Extended-release naltrexone (Vivitrol) prolongs addiction } \\
\hline \multicolumn{7}{|l|}{$\begin{array}{l}\text { Extended-release naltrexone (Vivitrol) should be used to maintain clients who have } \\
\text { opioid use disorder }\end{array}$} \\
\hline \multicolumn{7}{|l|}{$\begin{array}{l}\text { Extended-release naltrexone (Vivitrol) is more effective than non-pharmacological } \\
\text { approaches to retaining clients in treatment }\end{array}$} \\
\hline Extended-release naltrexone (Vivitrol) interferes with one's ability to drive a & & & & & & \\
\hline Extended-release naltrexone (Vivitrol) reduces or blocks the effect of heroin & & & & & & \\
\hline
\end{tabular}

\section{SOURCES OF INFORMATION ABOUT SUBSTANCE USE DISORDER TREATMENTS}

5. Have you previously received any formal education or training about Medication Assisted Treatment in your capacity as a court employee?*

- Yes

- No

\section{DEMOGRAPHICS}

6. What is your age?*

- 18-29 years old

- 30-49 years old

- 50-64 years old

- 65 years and over

7. What is your gender?*

- Male

- Female

- Other

8. What is the highest level of education you have completed?*

- Some high school

- High school graduate

- Some college

- Trade/technical/vocational training

- Associate degree

- Bachelor's degree

- Some postgraduate work

- Graduate or professional degree

9. Are you or a close family member in recovery from a substance use disorder?*

- Yes

- No

- Prefer not to respond

10. Which of the following best describes the area in which you live?*

- Urban

- Rural

\section{References}

Adult Drug Court Best Practice Standards (2018). Retrieved from https://www.nadcp. org/wp-content/uploads/2018/12/Adult-Drug-Court-Best-Practice-StandardsVolume-I-Text-Revision-December.

Andraka-Christou, B. (2017). What is treatment for opioid addiction in problem-solving courts? A study of 20 Indiana drug \& veterans courts. Stanford J. Civil Rights \& Civil Liberties, 13(2), 189-254.

Andraka-Christou, B., \& Capone, M. J. (2018). A qualitative study comparing physician- reported barriers to treating addiction using buprenorphine and extended-release naltrexone in U.S. office-based practices. International Journal of Drug Policy, 54. https://doi.org/10.1016/j.drugpo.2017.11.021.

Bruce, R. D., \& Schleifer, R. A. (2008). Ethical and human rights imperatives to ensure medication-assisted treatment for opioid dependence in prisons and pre-trial detention. International Journal of Drug Policy. https://doi.org/10.1016/j.drugpo.2007.11. 019.

Chandler, R. K., Fletcher, B. W., \& Volkow, N. D. (2009). Treating drug abuse and addiction in the criminal justice system: Improving public health and safety. JAMA, 301(2), 183-190. 
Davies, J. (2015, February 6). White house takes important first step toward fixing broken drug court system. Drug Policy Alliance. Retrieved from http://www.drugpolicy.org/ blog/white-house-takes-important-first-step-toward-fixing-broken-drug-courtsystem.

Dowell, D., Arias, E., Kochanek, K., Anderson, R., Guy, G. P., Losby, J. L., \& Baldwin, G. (2017). Contribution of opioid-involved poisoning to the change in life expectancy in the United States, 2000-2015. Jama, 318(11), 1065-1067. https://doi.org/10.1001/ JAMA.2017.9308.

Friedmann, P. D., Hoskinson, R., Gordon, M., Schwartz, R., Kinlock, T., Knight, K., \& Frisman, L. K. (2012). Medication-assisted treatment in criminal justice agencies affiliated with the criminal justice-drug abuse treatment studies (CJ-DATS): Availability, barriers, and intentions. Substance Abuse, 33(1), 9-18. https://doi.org/ 10.1080/08897077.2011.611460.

Gordon, M. S., Vocci, F. J., Fitzgerald, T. T., O'Grady, K. E., \& O'Brien, C. P. (2017). Extended-release naltrexone for pre-release prisoners: A randomized trial of medical mobile treatment. Contemporary Clinical Trials, 53, 130-136. https://doi.org/10. 1016/j.cct.2016.12.015.

Harper, J. (2017, August 3). To grow market share, a drugmaker pitches its product to judges. National Public Radio. Retrieved from https://www.npr.org/sections/health-shots 2017/08/03/540029500/to-grow-market-share-a-drugmaker-pitches-its-product-tojudges.

Hedrich, D., Alves, P., Farrell, M., Stöver, H., Møller, L., \& Mayet, S. (2012). The effec tiveness of opioid maintenance treatment in prison settings: A systematic review. Addiction. https://doi.org/10.1111/j.1360-0443.2011.03676.x.

Holzinger, A., Floris, F., Schomerus, G., Carta, M. G., \& Angermeyer, M. C. (2012). Gender differences in public beliefs and attitudes about mental disorder in western countries: A systematic review of population studies. Epidemiology and Psychiatric Sciences, 21(1), 73-85. Retrieved from http://www.ncbi.nlm.nih.gov/pubmed/22670415.

Jackson, H., Mandell, K., Johnson, K., Chatterjee, D., \& Vanness, D. J. (2015). Cost-effectiveness of injectable extended-release naltrexone compared with methadone maintenance and buprenorphine maintenance treatment for opioid dependence. Substance Abuse. https://doi.org/10.1080/08897077.2015.1010031.

Jarvis, B. P., Holtyn, A. F., Subramaniam, S., Tompkins, D. A., Oga, E. A., Bigelow, G. E., \& Silverman, K. (2018). Extended-release injectable naltrexone for opioid use disorder: A systematic review. Addiction, 113(7), 1188-1209. https://doi.org/10.1111/add. 14180

Józsa, K., \& Morgan, G. A. (2017). Reversed items in Likert scales: Flitering out invalid responders. Journal of Psychological and Educational Research, 25(1), 7-25. Retrieved from https://fac.ksu.edu.sa/sites/default/files/likert2_0.pdf.

Kelty, E., \& Hulse, G. (2017). Fatal and non-fatal opioid overdose in opioid dependent patients treated with methadone, buprenorphine or implant naltrexone. International Journal of Drug Policy, 46, 54-60. https://doi.org/10.1016/j.drugpo.2017.05.039.

Kjome, K. L., \& Moeller, F. G. (2011). Long-acting injectable naltrexone for the management of patients with opioid dependence. Substance Abuse: Research and Treatment, 5, 1-9. https://doi.org/10.4137/SART.S5452.

Krawczyk, N., Picher, C. E., Feder, K. A., Student, P., \& Saloner, B. (2017). Only one in twenty justice-referred adults in specialty treatment for opioid use receive methadone or buprenorphine. Health Affairs, 36(12), 2046-2053. https://doi.org/10.1377/ hlthaff.2017.0890.

Larochelle, M. R., Bernson, D., Land, T., Stopka, T. J., Wang, N., Xuan, Z., \& Walley, A. Y. (2018). Medication for opioid use disorder after nonfatal opioid overdose and association with mortality. Annals of Internal Medicine, 169(3), 137-145. https://doi.org/ 10.7326/M17-3107.

Lee, J. D., Friedmann, P. D., Kinlock, T. W., Nunes, E. V., Boney, T. Y., Hoskinson, R. A., \& O'Brien, C. P. (2016). Extended-release naltrexone to prevent opioid relapse in criminal justice offenders. New England Journal of Medicine, 374(13), 1232-1242. https://doi.org/10.1056/NEJMoa1505409.

Lee, J. D., Nunes, E. V, Novo, P., Bachrach, K., Bailey, G. L., Bhatt, S., ... Rotrosen, J. (2017). Comparative effectiveness of extended-release naltrexone versus buprenorphine-naloxone for opioid relapse prevention (X:BOT): A multicentre, open-label, randomised controlled trial. The Lancet. doi:https://doi.org/10.1016/S01406736(17)32812-X.

Lee, J. D., Nunes, E. V., Novo, P., Bachrach, K., Bailey, G. L., Bhatt, S., \& Rotrosen, J. (2018). Comparative effectiveness of extended-release naltrexone versus buprenorphine-naloxone for opioid relapse prevention (X:BOT): A multicentre, open-label, randomised controlled trial. Lancet (London, England), 391(10118), 309-318. https:/ doi.org/10.1016/S0140-6736(17)32812-X.

Ludwig, A. S., \& Peters, R. H. (2014). Medication-assisted treatment for opioid use disorders in correctional settings: An ethics review. International Journal of Drug Policy. https://doi.org/10.1016/j.drugpo.2014.08.015.

Mattick, R., Breen, C., Kimber, J., \& Davoli, M. (2014). Buprenorphine maintenance versus placebo or methadone maintenance for opioid dependence. Cochrane Database of Systematic Reviews, 2. https://doi.org/10.1002/14651858.CD002207.pub4.

Matusow, H., Dickman, S. L., Rich, J. D., Fong, C., Dumont, D. M., Hardin, C., \& Rosenblum, A. (2013). Medication assisted treatment in US drug courts: Results from a nationwide survey of availability, barriers and attitudes. Journal of Substance Abuse Treatment, 44, 473-480. https://doi.org/10.1016/j.jsat.2012.10.004.
Medications for Opioid Use Disorder TIP 63 Treatment Improvement Protocol For Healthcare and Addiction Professionals, Policymakers, Patients, and Families (2018) Retrieved from https://store.samhsa.gov/product/TIP-63-Medications-for-OpioidUse-Disorder-Full-Document-Including-Executive-Summary-and-Parts-1-5-/SMA18 5063FULLDOC.

Medications to treat opioid use disorder, \& National Institute on Drug Abuse (2018). Retrieved from https://www.drugabuse.gov/node/pdf/21349/medications-to-treatopioid-use-disorder.

Morgan, J. R., Schackman, B. R., Leff, J. A., Linas, B. P., \& Walley, A. Y. (2018). Injectable naltrexone, oral naltrexone, and buprenorphine utilization and discontinuation among individuals treated for opioid use disorder in a United States commercially insured population. Journal of Substance Abuse Treatment, 85, 90-96. https://doi.org/ 10.1016/j.jsat.2017.07.001.

National Institutes of Health (NIH) (2016). Rates of nonmedical prescription opioid use and opioid use disorder double in 10 years. Retrieved December 1, 2017, from https://www.nih.gov/news-events/rates-nonmedical-prescription-opioid-use-opioiduse-disorder-double-10-years.

Mehta, C. (2017). Neither justice nor treatment: drug courts in the United States, Physicians for Human Rights. Retrieved June 28, 2019, from https://phr.org/ resources/niether-justice-nor-treatment/.

Nielsen, S., Larance, B., \& Lintzeris, N. (2017). Opioid agonist treatment for patients with dependence on prescription opioids. Journal of the American Medical Association, 317(9), 967-968. https://doi.org/10.1001/jama.2017.0001.

Nordstrom, B. R., \& Marlowe, D. B. (2016). Medication-assisted treatment for opioid use disorders in drug courts ensuring the safe, effective, and responsible use of addiction medications for drug court participants. Drug Court Practitioner Fact Sheet, 11(2), Retrieved from https://www.ndci.org/wp-content/uploads/2009/04/mat fact sheet1.pdf.

Nunn, A., Zaller, N., Dickman, S., Trimbur, C., Nijhawan, A., \& Rich, J. D. (2009). Methadone and buprenorphine prescribing and referral practices in US prison systems: Results from a Nationwide survey. Drug and Alcohol Dependence. https://doi. org/10.1016/j.drugalcdep.2009.06.015.

Pariente, B. (n.d.). The Opioid Crisis and How Family Court Judges Can Respond. Retrieved from https://www.flcourts.org/Resources-Services/Court-Improvement/ Problem-Solving-Courts/The-Opioid-Crisis.

Potter, J. S., Marino, E. N., Hillhouse, M. P., Nielsen, S., Wiest, K., Canamar, C. P., \& Ling, W. (2013). Buprenorphine/naloxone and methadone maintenance treatment outcomes for opioid analgesic, heroin, and combined users: Findings from starting treatment with agonist replacement therapies (START). Journal of Studies on Alcohol and Drugs, 74(4), 605-613. https://doi.org/10.15288/jsad.2013.74.605.

Pretrial Diversion. (n.d.). Retrieved from http://www.ncsl.org/research/civil-andcriminal-justice/pretrial-diversion.aspx.

Results from the 2012 National Survey on drug use and health: Summary of National Findings.

Rich, J. D., Boutwell, A. E., Shield, D. C., Key, R. G., McKenzie, M., Clarke, J. G., \& Friedmann, P. D. (2005). Attitudes and practices regarding the use of methadone in US state and federal prisons. Journal of Urban Health, 82(3), 411-419.

Rosenblatt, R. A., Andrilla, C. H. A., Catlin, M., \& Larson, E. H. (2015). Geographic and specialty distribution of US physicians trained to treat opioid use disorder. Annals of Family Medicine, 13(1), 23-26. https://doi.org/10.1370/afm.1735.

Senator Harris Launches Investigation into Pharmaceutical Manufacturer Alkermes Regarding Opioid Addiction Treatment Manipulation (2017). Retrieved April 24, 2019, from https://www.harris.senate.gov/news/press-releases/senator-harrislaunches-investigation-into-pharmaceutical-manufacturer-alkermes-regardingopioid-addiction-treatment-manipulation.

Sharma, A., O'Grady, K. E., Kelly, S. M., Gryczynski, J., Mitchell, S. G., \& Schwartz, R. P. (2016). Pharmacotherapy for opioid dependence in jails and prisons: Research review update and future directions. Substance Abuse and Rehabilitation, 7, 27-40. https:// doi.org/10.2147/SAR.S81602.

Sordo, L., Barrio, G., Bravo, M. J., Indave, B. I., Degenhardt, L., Wiessing, L., \& PastorBarriuso, R. (2017). Mortality risk during and after opioid substitution treatment: Systematic review and meta-analysis of cohort studies. BMJ (Clinical Research Ed.), 357, j1550. https://doi.org/10.1136/bmj.j1550.

Sullivan, M. A., Bisaga, A., Pavlicova, M., Carpenter, K. M., Choi, C. J., Mishlen, K., .. Nunes, E. V. (2018). A randomized trial comparing extended-release injectable suspension and oral naltrexone, both combined with behavioral therapy, for the treatment of opioid use disorder. American Journal of Psychiatry, appi.ajp.2018.1. doi:https://doi.org/10.1176/appi.ajp.2018.17070732.

Tanum, L., Solli, K. K., Latif, Z.-H., Benth, J.Š., Opheim, A., Sharma-Haase, K., \& Kunøe, N. (2017). The effectiveness of injectable extended-release naltrexone vs daily buprenorphine-naloxone for opioid dependence. JAMA Psychiatry, 74(12), 1197-1205. https://doi.org/10.1001/jamapsychiatry.2017.3206.

Willis, G. B. (1999). Cognitive interviewing: A "how to" guide. 1999 meeting of the American Statistical Association. Research Triangle Park, NC: Research Triangle Institute.

Willis, G. B. (2005). Cognitive interviewing: A tool for improving questionnaire design. Thousand Oaks. California: Sage Publications. 